\title{
MISTRAL MISTRAL
}

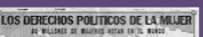

Journal of Latin American Women's

Intellectual \& Cultural History

\section{La tortuguita}

\section{Marjorie Agosín}

To cite: Marjorie Agosín. 2021. "La tortuguita" Mistral: Journal of Latin American Women's Intellectual \& Cultural History 1 (1): 12-24, https://doi.org/10.21827/mistral.1.37553 


\section{La tortuguita}

Un cuento por Marjorie Agosín

A Fernando e Isabel, mis primos

Nota de la autora:

Cuando visité a mis primos Fernando e Isabel en Santiago de Chile, también visitaba a Manuelita la tortuguita. Siempre iba en el verano del hemisferio sur y la encontraba entre las flores o a veces comiendo verduras. Muchas veces la tomaba entre mis brazos y me sentía muy feliz junto a ella. Les pregunté a mis primos sobre como llegó esta tortuguita a la casa de ellos y me contaron lo que relato en el cuento, que la trajo una señora del Norte de Chile y que a cambio de dinero por Manuelita pedía alimentos. Manuelita aun sigue viva y en casa de mis primos, pero yo decidi cambiar el final de la historia. Siempre pienso que las personas deben de regresar a sus entornos. El exilio es difícil para las personas, y los animales también aman lo familiar. Por esta razón, en el cuento se devuelve a la tortuguita a su lugar natal. Terminé de escribir esta historia unos meses antes de la Pandemia. En el tiempo del encierro global me acordé mucho de Manuelita porque las tortuguitas siempre andan despacio, porque aman la lentitud y siempre he creido que cuando invernan tratan de reparar a un mundo agitado. Ojalá que esta historia traiga paz y alegrías. Más que nada, que pensemos que siempre podemos regresar a casa, aunque sea en la imaginación.

\section{CAPÍTULO UNO}

Recuerdo que era un día asoleado con nubes que golpeaban la puerta traídas por el viento, algunas se colaban dentro de la casa dejando ese agradable frío que las caracteriza. Mamá, que estaba acostumbrada a caminar de un lado de la casa a; otra haciendo esto y aquello, se paró en seco ese día y salió al patio como si una voz misteriosa la hubiera llamado desde otro mundo.

Había una reja azul donde algunas amapolas crecían. Mamá se acercó a la reja y se puso a conversar con alguien que parecía ser una señora muy viejita. Pero desde donde yo estaba escondiéndome parecía también a una niña pues era bastante bajita. En mi imaginación de niña, la veía como una anciana y una niña al mismo tiempo, y pensé que finalmente había llegado "la niña vieja", un personaje inventado al que yo jugaba con mis amigas de la época. La señora traía en su mano una rosa negra y en su bolsa una alcachofa todavía más negra que la rosa. Al mirar su bolsa me di cuenta que la alcachofa se movía un poco y me dio algo de miedo, sin embargo, al mirar más de cerca noté que en realidad no era la alcachofa la que se movía sino algo bajo ella.

Mamá habría pensado lo mismo porque la oí preguntar, "Señora, ¿qué trae en ese bolso? Parece moverse". La anciana le respondió algo con una voz tan bajita que sus palabras se confundieron con los jirones de nubes que el viento dejaba sobre el patio. Su voz parecía no ser de este mundo sino del otro, de ese inmaterial donde me gustaba jugar.

"Aquí tengo a un regalo para Ud., señora. Es una tortuguita que acaba de nacer, le puse Manuelita". 
Mi madre se asombró bastante, puesto que a fin de cuentas no todos los días se conoce a una tortuga recién nacida, a una que apenas asomaba su cabecita al mundo.

“¿Y piensa regalármela, señora?”.

"Claro que se la regalo... pero me preguntaba si usted me puede dar un poquito de pan o arroz, o algunas semillas de amapolas. Veo que tiene muchas amapolas en su jardín".

Mi madre la miró pensativa. "¿De dónde viene tan arreglada, señora? Sus zapatos son tan lindos y nuevos".

"Muchas gracias. Quería presentar la mejor cara en este día tan especial", dijo la viejita con un brillo en la mirada.

Mamá siempre me había contado que los pobres llevan zapatos nuevos cuando quieren mostrarle respeto a alguien. En ese momento mi madre parecía confundida y conmovida a la vez por la apariencia repentina de la viejita, su muestra de cortesía, y su regalo inesperado. Tocó el hombro de la señora en una manera reconfortante que parecía comunicarle Eres bienvenida aqui señora. Gracias por escoger nuestra casa.

La viejita le dio otra sonrisa resplandeciente a mi madre. "Vengo del lejano norte. Soy vieja, curtida por el sol de Antofagasta. Creo que el frío hizo que me achicara. De joven era alta, ipero ahora soy diminuta! Apuesto que Ud. se preguntaba si era niña o vieja cuando me vio por primera vez. Creo que soy las dos cosas al mismo tiempo: medio niña y medio vieja. Y de tanto vivir entre las tortugas ya camino como ellas, bien despacio... Pero señora linda, recíbame esta tortuguita. Ella es especial y he estado buscando la familia perfecta para cuidarla. Veo a una niña escondida ahí. Tal vez Manuelita sea para ella. Es su hija, ¿no?’”.

Desde lejos veía que ellas hablaban y que mi madre me hacía señas con las manos, yo estaba escondida entre las cortinas donde solía desaparecer de los demás o cuando había mucho ruido en la casa. En ese rincón yo era una princesa o alguna hada con una pila de cosas a cuestas. De niña me gustaba soñar despierta y quedarme absorta en los infinitos y circulares galerías de los caracoles de mar y el patrón floral de las cortinas, que imaginaba que, una vez abiertas, conducían a un bosque exótico lleno de coloridos flores. Al ver que mi madre insistía salí de mi escondite y fui al patio. Cuando me acerqué vi que la anciana sacaba la tortuguita de su bolso café.

“Se llama Manuelita. ¿Te gusta?” me preguntó la señorita, mostrándome el animalito. De inmediato estaba intrigada y la quise tomar en mis manos. La cabeza de la tortuguita se movía de un lado al otro. A veces decía sí y a veces decía no, pero con su cabecita. Cuando la señora por fin la colocó entre mis manos Manuelita me miró con sus ojitos y la quise al instante.

Mi madre entró a la casa a buscar algunas cosas para darle a la señora: un kilo de harina, uno de arroz y unas semillas de amapola que de inmediato ella guardó en un bolsillo medio escondido de su falda. Mamá le preguntó si se quedaría en Santiago y la anciana le dijo que nunca tenía la certeza sobre esas cosas, que se dejaría llevar por donde el viento quisiera que fuera y que siempre había gente amable que le ofrecía una pieza donde quedarse. A la larga regresaría al norte para cuidar de las otras tortugas que vivían allí. Luego le puso algo en la mano de mamá y le besó la mejilla. Sin decir otra palabra, dio la vuelta y así como llegó, con ese paso lento de tortuga, fue desapareciendo en el camino, como un espejismo.

Nunca me pregunté por qué la viejita había elegido nuestra casa, pero entendí a mi manera que las preguntas relacionadas a las cosas misteriosas y bellas no se deben ni preguntar ni contestar. 


\section{CAPÍTULO DOS}

En aquellos días Manuelita era tan pequeña que me cabía en mi mano de niña, pero lo que más me llamaba la atención era su coraza pues parecía una pequeña maleta circular, una cajita pintada con muchos cuadritos de colores en tonos cafés y también de algunos verdes todo bañado por un polvillo de color cobre, como la tierra de ese desierto rocoso de donde venía, allá en el norte lejano.

Yo todavía no conocía bien los detalles de aquel paisaje al que llamamos Chile donde vivía con mamá, papá, la abuela Mercedes, y mis hermanos. No sabía casi nada de sus regiones, menos de sus capitales, tan solo generalidades que había aprendido en mis primeros años del colegio, aunque tengo que confesar que la escuela fue donde iba más bien a jugar con mis compañeras que a aprender. No tenía ni idea de por qué al lugar donde Manuelita nació le decían Norte Grande, pero cuando tenía a Manuelita en mis manos y observaba las vetas y colores de su caparazón me imaginaba los cerros en donde vivía la señora que la trajo.

También imaginaba el interior de esos cerros y toda la majestuosa infinidad de minerales que paseaban por ahí como lenguas de lava encendida cayendo por los valles hasta llegar al mar donde se transformaban en rocas que después servían de casa a los caracoles, a los cangrejos, a las inmensas jaibas y también quizás a otras tortugas como mi Manuela. Los caminitos que tenía en su espalda y esas regiones extrañas que se dibujaban sobre ella me parecían el mapa perfecto para un Chile que crecía en mi imaginación. Cuando estaba junto a ella nada parecía tan lejano, ni las islas de Chiloé - las islas más apartadas de mi país repletas de loros anaranjados y de magia — ni las alturas del Aconcagua, ni el Salar de Atacama y su desierto, ni la pampa en el extremo sur. Todo confluía en esa cartografía maravillosa que en Manuelita crecía sobre su espalda. Así, con los años fui aprendiendo una geografía todavía más inmensa que la aprendida en el colegio. Y hoy cuando me preguntan por los paisajes de Chile yo siempre respondo pensando en mi amiga de niña, Manuelita. 


\section{CAPÍTULO TRES}

Cuando Manuelita empezó a vivir con nosotros, mamá sugirió que la tortuguita probablemente preferiría quedarse en el jardín, iy tenía toda la razón! Manuelita se sentía feliz acompañada por las hortensias, las plantas de tomates, las alcachofas y las zanahorias. A Manuelita le gustaba mucho pasear entre las plantas y perseguir a los gusanos que andaban por ahí con la parsimonia del hacendado, como los grandes señores del jardín. La única cosa que a Manuelita no le gustaban mucho eran las amapolas. Las evitaba y nunca las mordía. Tal vez el fulgor de las amapolas la impresionaba, tal vez la asustaba esa forma medio hipnótica que tienen, como recién salidas del sueño de un pintor.

Manuelita mordisqueaba varias cosas ricas en el jardín, pero si no estaban muy frescas pasaba de largo y no las tocaba. Aun las tortugas tienen sus propios gustos, pensaba yo mientras la miraba comer y pasear. Le gustaban mucho las hojas del repollo, sobre todo si estaban recién bañadas con el rocío de la mañana, también las zanahorias anaranjadas como la primavera. No era muy aficionada a los tomates eso sí, y menos al cilantro. Al parecer, todo lo que fuera demasiado verde no le interesaba.

En los veranos se inclinaba por las sandias, por las jugosas, por esas de pepitas finas y si hay algo que amaba por sobre todas las cosas, incluso más que dormir, eran los duraznos. Así pues, las poníamos entre las hortensias y las zanahorias y ahí quedaba Manuelita feliz paseando y comiendo en lo que yo imaginaba que era su propio bosque personal. 


\section{CAPÍTULO CUATRO}

Cuando llegó el primer invierno que Manuelita estuvo con nosotros, mamá me dijo algo raro. "Hija, necesitas guardar a la tortuguita un rato". No entendí así que mamá me explicó que Manuelita necesitaba echar una larga siesta. En realidad, usó la palabra "hibernar". Puesto que todavía no entendí mi madre me lo explicó con el ejemplo de los osos que duermen hasta la primavera.

Busqué una caja de zapatos en que mi tortuguita podría quedarse dormida por varios meses - itanto tiempo! Un día cuando el frío parecía entrar por todas partes de la casa fue la señal de que debía estarse quieta en su caja mágica donde seguramente soñaría con las hortensias y las misteriosas amapolas hasta despertarse en la primavera.

¡Recién había llegado a casa y ahora había que guardarla! Aquello no me parecía justo en lo absoluto. No quería estar sin ella todo el invierno. Sin embargo, con la ayuda de mamá, entendí que las cosas que se ocultan no desaparecen sino que siempre están ahí. Me dijo que basta con recordarlas para que otra vez vuelvan a nuestro pensamiento, y así tomé a Manuelita entre mis manos y me despedí de ella con un abrazo y un beso en su lindo caparazón. La acomodé en su cajita con un poco de pasto seco que mamá había encontrado en el patio. La guardé en el ropero donde estaba acurrucadita y calentita y donde podía mirarla cuando quisiera para averiguar que estaba bien. La observaba por minutos muy largos intentando adivinar con que estaría soñando mi tortuguita.

"M'ija no creo que las tortugas sueñen", me dijo mamá mientras revolvía una mermelada de duraznos con una inmensa cuchara de palo.

"Mamá, todos soñamos, incluso las tortugas", le respondí con autoridad. "Creo que Manuelita está soñando con la mermelada que estás haciendo. Sabes cuánto le gustan los duraznos. Apuesto que está soñando con comérselos en septiembre cuando se despierte”. Mi madre sonreía como queriéndome decir muchas cosas al mismo tiempo con su mirada.

Durante ese invierno mi hermana y yo siempre íbamos muy despacito a ver a Manuelita dormida en su cajita de zapatos. No queríamos despertarla. Manuelita siempre estaba ahí con su caparazón que brillaba como si tuviera una lucecita dentro. Le dábamos un beso y le contábamos de la mermelada. Siempre ella estaba muy quietita y hasta el viento parecía calmarse un poco cuando estábamos con ella como ayudándonos a no despertarla de su sueño de duraznos.

A veces cuando mi hermana se iba para jugar en otra parte de la casa me quedaba un rato más con mi tortuguita admirándola e imaginando que mientras las personas y los animales duermen en la oscuridad se llenan de la belleza y la luz de los sueños. Luego traía mi frazada y una almohada de plumas que mi abuela me había traído de otro país y me acostaba junto a ella. De tanto observarla, aprendí que Manuelita tenía su propio brillo en la oscuridad que iluminó mi corazón, especialmente en esos meses largos de invierno cuando añoraba estar en el jardín con ella. No nos decíamos nada en esas ocasiones porque entre nosotras no eran necesarias las palabras. A veces pensaba que Manuelita movía una patita pero la verdad es que no se movía en absoluto, simplemente siguió durmiendo en su cajita de zapatos que mi madre había pintado de azul.

Sabía que cuando los jazmines del cabo florecían y mi padre tomaba algún botoncito para dejarlo en las almohadas, ya era el tiempo de despertar de su largo sueño. También sabía que lo primero que iba a hacer era asomar esa cabecita somnolienta. Se iba a mover muy pero muy despacio por un par de días porque a las tortugas les cuesta reponerse de la hibernación. 


\section{CAPÍTULO CINCO}

El primer invierno parecía ir más lento que lo habitual, tal vez como los pasos que Manuelita daba en el jardín, pero un día por fin el invierno terminó y la tortuguita empezó a despertar. Se movía muy lentamente, con movimientos que eran casi imposibles de observar, primero una patita, luego la otra y finalmente empezaba a sacar la cabecita. Yo pensaba que en algún momento iba a bostezar pero no ocurrió así. Al principio se despertaba como si se movía en cámara lenta pero luego de repente es despertó del todo. Después de saludarla la tomé entre mis manos para llevarla al jardín. Noté que había crecido en su cajita porque ya no parecía tan diminuta entre mis manos y los colores en el caparazón brillaban más que antes. Cuando la puse en el patio fue directamente, aunque lentamente, al césped donde parecía bailar entre las briznas con gracia. Me divertí mirándola mientras iba de aquí para allá con su elegancia de tortuga.

Los primeros dos días que estaba despierta, se movía con la elegancia propia de la lentitud, al contrario de la gente que va de prisa de un lugar a otro sin notar los aspectos más importantes de la vida. La genta, a diferencia de las tortugas, aun se despiertan de forma apurada. Apenas toman el café y parten de sus casas siempre cargando bolsas y esos teléfonos inteligentes pegados a las orejas como si fueran un estilo de apéndice. Papá dice que esos teléfonos deben de ayudarnos a formar conexiones con la gente pero me parece que en realidad distancian cada vez más a las personas. Debemos de aprender de nuestros amigos las tortugas que toman su tiempo y disfrutan de las cosas asombrosas en la vida, y que saben cuándo deben comunicarse con los demás y cuándo es hora de guardarse por algunos meses.

Mientras que Manuelita iba creciendo cada año, otras cosas se achicaban como mi abuelita que aún no estaba en el cielo. Cuando empezó a envejecer también empezó a achicar. Era cada vez más pequeña y tenía el rostro como una pasita, de esas que mamá ponía en los queques de pasas. ¡Claro que a mi abuela Mercedes nunca la hubiera puesto en una torta! Se puso tan diminuta que pude ponerla en una de las canastas grandes que mamá usaba para hacer la compra y sacarla al jardín donde le encantaba mirar a Manuelita pasear entre las hortensias.

Después de unos años, mi madre empezó a achicarse también. Pero la cosa más extraña ocurrió: mientras ella se achicaba hablaba más y más alto. Cada vez que hablaba asustaba a Manuelita que daba un saltito. Pronto los miembros mayores de mi familia empezaron a parecer pequeñas velas que poco apoco se apagaban. Mientras que ellos se hacían más chicos y viejos Manuelita estaba ahí tan fuerte y tan segura de sí misma que me parecía que ella era quien nos iba a sobrevivir.

Con el tiempo todo fue cambiando. La abuela Mercedes que siempre quería salir al patio para mirar a Manuelita un día en el mes de septiembre, el de los volantines en Chile, cerró los ojos y se fue al cielo. Cuando yo sentía mucha pena después de la muerte de la abuelita solía acariciar el caparazón de Manuelita e imaginar que mi abuela plantaba flores en el cielo para preparar un sitio para Manuelita para cuando ésta estaba lista para reunirse con ella. Pues para llegar al cielo uno se demora un poco ya que alguien tiene que adornar el sitio para ti, al igual que imaginaba que la abuelita hacía para Manuelita. 


\section{CAPÍTULO SEIS}

Mis hermanos fueron creciendo y llegado el momento se casaron yéndose para siempre de la casa. Yo al contrario no quería crecer porque amaba a Manuelita y quería quedarme en casa con ella para siempre. Sin embargo, un día mis papás me dijeron que tenía que irme para recibir una buena educación. Por un tiempo me fui a vivir a otro país. Aunque quería llevar a Manuelita conmigo, tuve que dejarla en el hermoso patio de mi infancia. Mamá me prometió que cuidaría a mi tortuguita mientras estaba lejos. Sabía que iba a echar de menos a mamá y a Manuelita con todo mi corazón.

Es curioso cómo uno puede enamorarse tan completamente de algo o alguien. Para mí fue la tortuguita pero para otros puede ser un elefante, alguna flor, o una persona. Ahora me doy cuenta que siempre amé a mi tortuga Manuelita porque la sentía tan débil y delicada. Lo mismo me pasa con otros animales también y a lo largo de los años las personas con quienes he vivido me han criticado porque decían que me preocupaba más por los perros y los gatos que las personas. Yo creo que hago bien en preocuparme por los animales porque ellos no pueden hablar por sí mismos y necesitan de alguien que hable por ellos y que exprese lo que necesitan y lo que quieren para que puedan vivir una buena vida.

Después de unos años de estudiar, regresé a Chile. Había extrañado tantas cosas de mi infancia, cosas que no tienen contornos muy definidos y que son difíciles de explicar, pero que son parte de quien soy. Por ejemplo, extrañé la niebla siempre presente que vuela bajito y hace difícil ver y los relojes viejos en la casa de mi niñez que marcaban el paso del tiempo. El ir y venir de la niebla y el tictac de los relojes me hicieron recordar quien fui y también me permitieron regresar a otro tiempo cuando llevaba a Manuelita al parque donde las viejitas se sentaban a mirar el paso de las horas. A veces la tortuguita se alejaba de mí y la perdía de vista, pero sabía que ella siempre estaba cerca. De vez en cuando me miraba de reojo con su cabecita de tortuga para que la pudiera ver entre las briznas. Añoro tanto esos tiempos más sencillos. 


\section{CAPÍTULO SIETE}

Pasaron muchos veranos y las hortensias se ponían cada vez más moradas. Todas las plantas en el jardín de mis padres crecían: las albahacas, las fresias y los irises. A Manuelita le gustaba olfatear estas flores pero la cosa que más le gustaba hacer fue comer. Además del repollo, le gustaba comer insectos, especialmente los que eran largos y delgaditos. Recuerdo cómo almorzaba en el patio usando sus patitas como si fueran un tenedor y un cuchillo.

Así pasaron las horas, los días y los años, y los árboles crecieron mucho como si quisieran tocar cielo con sus ramas. Mis papás se hicieron aún más chiquitos hasta que decidieron cambiarse de casa a un departamento. Con esa noticia me asusté un poco. ¿Qué íbamos a hacer con Manuelita? No la podíamos llevar a una casa sin jardín, sin historias, sin insectos... la pobre se moriría de pena porque había hecho su vida en ese lugar, lo conocía como a las vetas de su caparazón y era tan independiente yendo de aquí para allá en el jardín. Los vecinos la conocían y la saludaban cuando la veían acercarse a la reja azul. Los perros del vecindario la saludaban también y olfateaban su caparazón alegremente.

Estaba muy aliviada cuando mis padres me dejaron a cargo de cuidar la casa y a Manuelita. Sabía que con Manuelita no me sentiría sola. Tengo que confesar que para mí era fácil pasar largos períodos sin hablar con nadie. Me encantaba leer y transportarme a lugares interesantes gracias a las historias de otros.

Después de pasar mucho tiempo con Manuelita, fui aprendiendo a mirar las cosas como ella. Aprendí a conocer el ritmo que tenía frente a la vida y lo fui adaptando a mi propia forma de ser. En cierta medida la tortuguita me iba enseñando a vivir libremente y no tomar tan en serio las cosas que pasaban a mi alrededor. 


\section{CAPÍTULO OCHO}

Manuelita sobrevivió a mis abuelos y a mis padres. Las tortugas son muy sabias y por eso tienen vidas tan largas. ¿Me sobreviviría a mí también? Y si era de esa forma ¿Quién la cuidaría? Aquello me quitaba el sueño pero a Manuelita parecía no importarle mucho porque seguía tal cual con su ritmo de vida, con su casita que llevaba a cuestas y con sus largos sueños de invierno. Cada primavera se despertaba cuando era hora, lista para explorar el mundo de nuevo.

Su caparazón cada vez más hermoso y lleno de historias, con esas vetas que crecían con los años y que parecían encerrar mi propia historia, mis recuerdos y las escenas de cuando recién llegó, parecía mostrarme todas las cosas que había aprendido con los años como si las líneas de su coraza fueran el libro donde yo había inscrito todo aquello que había amado.

A pesar de todo el amor que tenía por mi tortuguita un día la tuve que dejar otra vez. Tuve que mudarme a otro país para ganarme la vida. Aunque Manuelita era solo un animalito, dejarla una segunda fue una de las cosas más difíciles y tristes que he hecho en mi vida. Yo feliz me hubiese quedado en esa casa cuidando de mi tortuga pero tenía que empezar a vivir mi vida y escribir mis propias historias.

Sabía que esta vez ya sería un tiempo más largo y, tal vez, para siempre. Manuelita ya tenía sus años y llevarla a un país del norte hubiese sido provocarle un sufrimiento mayor al mío. Con el dolor de mi alma la tuve que dejar con unos nuevos inquilinos que me prometieron cuidarla y la casa de mis padres.

Con el pasar de los años lo que más añoraba de Chile, aparte de mis padres, era mi Manuelita. Sin embargo, tuve mucha suerte porque los nuevos habitantes de la casa me mandaban cartas con fotos de la tortuga para que yo estuviera tranquila. Mirar esas fotos de Manuelita paseando entre las briznas y olfateando las flores me hizo sentir feliz.

Un par de años después mis padres se murieron y regresé a Chile para enterrarlos y despedirme de ellos y para visitar a Manuelita. Era raro regresar a la casa de mi infancia donde solo quedaban las memorias que conservaba de los días de niñez, una que otra marca en la pared y ciertamente, Manuelita. Al salir al patio pude verla tranquila en la sombra de una hortensia. Al principio no fue muy efusiva conmigo pero eso no me importaba porque de cualquier forma sentí que me esperaba, que ella también quería verme. Me acerqué muy despacio a su bello caparazón y lo besé. Fue solo entonces que empezó a mover sus patitas y me sonrió con la cabecita que movía de un lado a otro. 


\section{CAPÍTULO NUEVE}

Después de esa visita, trataba de ir siempre en el mes de septiembre porque en esa fecha Manuelita se despertaba y además era mi mes favorito para encumbrar volantines, aunque más bien para mirarlos porque nunca fui muy buena con el volantín. De todos modos, me encantaba verlos volar con sus colores tan vibrantes por el cielo azul de Chile. Septiembre es un mes de nuevos principios, el fin del invierno, y la promesa de las cosas por venir.

Cuando llegaba a la casa de mis padres en esas visitas, los hijos de los inquilinos me mostraban cómo cuidaban a Manuelita. Eran cariñosos con la tortuguita y habían conservado en buen estado su cajita-casa para los descansos anuales de Manuelita. Cuando miraba a los niños jugar con la tortuguita podía oír las sabias palabras de mi madre cuando me decía M'ija, todas las personas en esencia son buenas pero en especial los niños, y claro, era de esa forma, porque en esas visitas los niños de la casa no paraban de hablarme de la tortuguita y de todas los cuidados que le daban. Todo eso me daba un poco de risa porque me acordaba de lo insistente que era yo de niña con los asuntos de Manuelita. Todo eso me provocaba un enorme alivio porque todo lo que ella representaba para mí estaría muy bien custodiado con ellos.

Durante mis visitas me daba cuenta una y otra vez que Manuelita guardaba en ella — en su caparazón-maleta y en su alma - todos los recuerdos de los tiempos felices que habíamos pasado juntas. Ella era un recuerdo vivo de esos tiempos. No tendría que andar buscando esos recuerdos en ciudades extrañas, en lugares donde hablaban idiomas que no entendía, en los árboles entumecidos o la copiosa nieve que caía. Solo tenía que regresar en mi mente al sitio donde esos recuerdos originaron - a la casa de mi infancia y a mi Manuelita.

Años después, muchos años después, ya cansada del trabajo que hacía, un día decidí hacer mi maleta y despedirme para siempre de mis colegas que nunca llegaron a ser amigos. Solo les interesaba mirar sus teléfonos inteligentes y el reloj en la pared anticipando el fin del día laboral. Empaqué mis pocas pertenencias y tuve la certeza de que en el país del norte nadie me echaría de menos ni dejaría huella alguna, pues mi destino era ir a pasar los últimos años de Manuelita en su compañía. 


\section{CAPÍTULO DIEZ}

Cada vez que volvía a casa después de una larga ausencia, la cordillera de los Andes me parecía más impresionante y me fascinaba. Tal vez la nostalgia había crecido en mí con los años, eso dicen, y por eso esas montañas me impactaban tanto. Aparte de lucir grandiosas también semejaban un enorme pastel de leche nevada como el que hacían mi abuela y mi madre. Ese postre tiene natillas cubiertas de picos de merengue espolvoreados de canela.

Aunque mi abuela y mi madre ya no están aquí, recobran vida en mi imaginación cada vez que veo a los Andes o uso uno de los dichos que decían. Creo con toda mi alma que las personas que han pasado a otra vida siguen vivas y reales en nuestros recuerdos. Por ejemplo, a veces cuando llueve, las gotitas que se pegan a la ventana forman una imagen que me hace recordar la cara de mi papá. En esas ocasiones imagino que papá ha regresado a visitarme y que cada gotita de agua es un mensaje o la nota de alguna canción que papá está tocando en un piano acurrucado en una nube en el cielo.

Regresé a Chile por última vez durante el largo invierno. Cuando llegué a casa encontré a Manuelita durmiendo intensamente. Su cajita estaba deshaciéndose de a poco y ya era tiempo de comprarle una casita nueva, tal vez con una pequeña puerta para deslizar mi mano y acariciar su caparazón. Tal vez pondría dentro algo de musgo para que Manuelita tuviera un colchón cómodo donde descansar durante los inviernos.

Estar en casa de nuevo fue maravilloso. Me sentía tranquila. Reconocía a las estrellas en el cielo claro chileno y las fragancias familiares de mi país. El momento de mi regreso también era oportuno pues por suerte los inquilinos que habían cuidado de Manuelita habían decidido mudarse dejándome a mí a cargo de la casa de mis padres otra vez. Mi antigua pieza era cómo la recordaba con su ventana por la que entraba la luz más brillante por las mañanas y el velador donde todavía estaban mis libros de poesía. Ese día me senté en mi antigua cama e imaginé que el tiempo se había detenido, que nunca tuve que irme, y que todos estarían abajo esperándome. Era un pensamiento agridulce lleno de amor y tristeza al mismo tiempo.

Un par de días después de mi llegada Manuelita por fin se despertó. De inmediato me reconoció, sacó su cabecita y me besó con su lengua fina y delgadita. Yo la apreté un buen rato y imaginaba que ella se reía, que le salía una lagrimita bien lenta, una lágrima de tortuga feliz pensé, y me largué a reír con ella.

Esa primavera fui muy feliz, Manuelita me enseñó el valor de la tranquilidad y la permanencia, me enseñó que las cosas simples y tranquilas como salir al jardín a tomar aire fresco o conversar con una vecina y tomar un té eran los asuntos más importantes en la vida. Me acostumbré rápidamente al ritmo único de mi país. Lo que más gozaba-aparte de pasar tiempo con Manuelita - era conversar con las vecinas que me contaban las mismas historias que había escuchado de niña tantas veces, pero daba igual porque amaba esas historias. Tal vez porque la permanencia me gusta y más que nada la lentitud de las cosas como los pasos de mi tortuga que se habían vuelto aún más lentos.

Un día, varios años más tarde, supe por instinto que había llegado el tiempo de regresar a Manuelita al lugar de donde venía, al norte donde las noches son muy largas y frías, donde el calor del mediodía es intenso. La geografía de ese lugar estaba inscrita en las vetas del caparazón de mi tortuguita. Sus recuerdos conmigo también estaban inscritas en esa cartografía única que llevaba en la espalda. Sabía que necesitaba regresarla al lugar de su nacimiento y a la señora que nos la había regalado hace tantos años para que pudiera tomar el próximo paso en su viaje. 
Y así una mañana partimos rumbo al norte en un bus verde y lento, aunque mirando el paisaje todo fue más veloz y las horas pasaron rápidamente mirando unos cerros verdes y frondosos que luego se transformaban en grandes extensiones más bien ocres y amarillas, anaranjadas tal vez, como las primeras vetas de Manuelita. Luego algo raro ocurrió. Cada vez que la topografía cambiaba, notaba que el caparazón de Manuelita cambiaba de tono también y que coincidía con los colores que estaba viendo por la ventana del bus. Me parecía algo mágico o una señal de algún tipo. Fue como si Manuelita formara parte de la geografía a nuestro alrededor. Ella regresaba a sus orígenes.

A pesar de los años que habían pasado desde que Manuelita había llegado a nuestra casa, mamá había conservado la dirección de la señora que nos había regalado la tortuguita cuando yo era niña. Recordaba en mi memoria que esa señora le había dado algo a mamá ese día mágico cuando vino a visitarnos. Mamá había puesto el papelito con la dirección en otra caja de zapatos semejante a la en que dormía Manuelita durante los inviernos.

Llegamos cansadas pero alegres al pueblo donde Manuelita había nacido. En un comienzo me costó dar con la casa, de hecho tuve que preguntar varias veces a los que vivían allí, pero al verme con la tortuga supieron de inmediato dónde me dirigía y me señalaron el camino.

Apenas llamé a la puerta de una casa diminuta cuando se asomó la cara de alguien que reconocí de inmediato. Aunque el tiempo había cambiado su rostro, como el mío me imagino, sabía que había dado con la señora que buscaba, la que me había dado un regalo tan precioso hace años. Me costó creer que todavía estaba viva porque ya era vieja cuando apareció por primera vez en nuestra casa. Ahora era vetusta y me preguntaba si había estado esperando el regreso de Manuelita para tomar el próximo paso en su vida.

Tan pronto como la señora nos vio dijo, "Sabía que algún día vendrían, lo supe el mismo día que dejé a la tortuguita en tu casa cuando saliste desde detrás de las cortinas donde te escondías para saludarnos. También lo sabía porque he estado soñando con ustedes". Nos miró por mucho tiempo y en sus ojos vi una mezcla de paz y amor. En ese momento supe que había hecho la cosa correcta en devolver a Manuelita a su casa. 


\section{CAPÍTULO ONCE}

La señora nos acomodó en el suelo sobre un colchón junto a una ventana donde podíamos mirar las estrellas que parecían unos enormes ojos azules en el cielo. Así nos dormimos, Manuelita y yo, abrazadas. Al día siguiente Manuelita se recuperó del letargo que le había producido el viaje, y vi que le gustaba sentir el frío y el calor de ese lugar porque su caparazón empezó a mimetizarse con los colores del norte chileno. Los ocres, amarillos y un naranjo que se parecía al color sepia de las fotos antiguas que guardan las memorias para siempre.

Pasaron los días y sabía que ya tenía que volver y dejar a Manuelita con la señora. Me provocaba una profunda tristeza tener que dejar a Manuelita para siempre, pero sabía que todo, a fin de cuentas, debe volver a su sitio, así como nosotros volvemos a la tierra que nos recibió cuando sentimos la cercanía de la muerte.

Me despedí de la señora con un beso en esa áspera mejilla curtida por el sol, tomé a Manuelita y le di un profundo y sentido abrazo como la primera vez que llegó a mi vida. Algo me dijo que no la volvería a ver y una ola de tristeza se apoderó de mí. Sin embargo, al mismo tiempo pensé que cuando uno ama no se despide de nadie pues nuestros seres queridos a pesar de todo siempre están a nuestro lado. Basta llamarlos para que regresen en nuestra memoria.

Salí de la casa y empecé a caminar lentamente por la calle que conducía al paradero. A pesar de la tristeza no pude dejar de darme la vuelta para ver a Manuelia por última vez. A la distancia, mi tortuguita se despedía con sus patitas en brazos de la señora. Luego vi que sacaba su lengüita para decirme también adiós. Le contesté en mi mente, Adiós amiga querida. Te amaré para siempre, esperando que me podía oír y entender.

Al regreso me esperaban todas las cosas que representaban mi futuro: mi trabajo, los estudios... mi vida a fin de cuentas. Manuelita y yo habíamos vivido tanto tiempo juntas y aunque tuvimos que despedirnos, nuestro amor siempre quedó entre nosotras. Era un amor lento y persistente como los movimientos de Manuelita, como esa forma de caminar que tenía, con mucha gracia y lentitud. Y eso finalmente fue lo que aprendí de ella, a mirar las flores de nuestro jardín sin apuros, a mirar los detalles y las vetas de todas esas manifestaciones de la vida que nos rodean y que a veces pasamos por alto, a observar el mundo sin esa prisa que no nos conduce a nada. En fin, a vivir la vida así, a paso de tortuga como se dice.

\section{FIN}

